\title{
Impacts of forest fragmentation on the mating system and genetic diversity of white spruce (Picea glauca) at the landscape level
}

\author{
LM O'Connell $^{1}$, A Mosseler ${ }^{2}$ and OP Rajora ${ }^{1}$ \\ ${ }^{1}$ Canada Research Chair in Forest and Conservation Genomics and Biotechnology, Faculty of Forestry and Environmental Management, \\ University of New Brunswick, PO Box 44555, 28 Dineen Drive, Fredericton, New Brunswick, Canada E3B 6C2; ${ }^{2}$ Natural Resources \\ Canada, Canadian Forest Service - Atlantic Forestry Centre, PO Box 4000, Fredericton, New Brunswick, Canada E3B 5P7
}

\begin{abstract}
We studied the mating system of white spruce (Picea glauca) in a landscape fragmented by agriculture in northern Ontario, Canada. We sampled 23 stands that ranged in size from 1 to $>500$ trees isolated by $250-3000 \mathrm{~m}$ from the nearest other stand. Six polymorphic allozyme loci from four enzyme systems were used to genotype approximately 10000 embryos from 104 families. We detected no allele frequency heterogeneity in the pollen pool among stands or families $\left(\Phi_{\mathrm{FT}}=-0.025\right)$. Overall, estimates of outcrossing were high $\left(t_{\mathrm{m}}=94 \%\right.$ and mean $\left.t_{\mathrm{s}}=91 \%\right)$ but significantly different from unity. Bi-parental inbreeding $\left(t_{\mathrm{m}}-t_{\mathrm{s}}=3.2 \%\right)$ was low but significantly different from zero. Allozyme-based outcrossing estimates did not differ significantly among three stand-size classes (SSCs): small ( $<10$ trees), medium (10-100 trees) and large ( $\geq 100$ trees). The number of effective pollen
\end{abstract}

donors was high in all SSCs, but was significantly lower in small stands $\left(N_{\mathrm{ep}}=62.5\right)$ than in medium-sized and large stands (both $N_{\mathrm{ep}}=143$ ). The primary selfing rate was significantly higher in medium stands than in large stands. We found no significant difference in genetic diversity measures in the filial (seed) population among SSCs. Overall, these results indicate that white spruce stands in this fragmented landscape are resistant to genetic diversity losses, primarily through high pollen-mediated gene-flow and early selection against inbred embryos. We discuss the importance of using seed data, in conjunction with genetic data, to evaluate the impacts of fragmentation on natural populations.

Heredity (2006) 97, 418-426. doi:10.1038/sj.hdy.6800886; published online 16 August 2006

Keywords: conifer; forest fragmentation; genetic diversity; mating system; pollen pool; white spruce

\section{Introduction}

One of the main objectives of genetic resource conservation is to maintain genetic diversity in natural populations to ensure the continued survival, fitness, and evolutionary potential of a species. Forest fragmentation can affect pollen-mediated gene dispersal, and consequently the mating system of trees, and the genetic diversity and structure of the resultant seed population. The study of the genetic consequences of forest fragmentation in natural plant populations has received increasing attention over the last decade (Hall et al, 1996; Young et al, 1996; Nason and Hamrick, 1997; Collevatti et al, 2001; Cascante et al, 2002; Fuchs et al, 2003; Bacles et al, 2004). Possible negative genetic impacts of fragmentation in plants include increased inbreeding and reduced genetic diversity caused by increased genetic drift and reduced gene flow between fragments (Young et al, 1996). In several herbaceous species, reproductive success decreases with a decrease in population size, either because of pollen-limitation or

Correspondence: LM O'Connell, Canada Research Chair in Forest and Conservation Genomics and Biotechnology, Faculty of Forestry and Environmental Management, University of New Brunswick, PO Box 44555, 28 Dineen Drive, Fredericton, New Brunswick, Canada E3B 6C2. E-mail: oconnell@unb.ca

Received 10 March 2006; accepted 18 July 2006; published online 16 August 2006 an increase in inbreeding in small populations (Vergeer et al, 2003; Reed, 2005).

Much of the research on the impacts of forest fragmentation on tree mating systems has been conducted on tropical species (eg Hall et al, 1996; Nason and Hamrick, 1997; Collevatti et al, 2001; Cascante et al, 2002; Fuchs et al, 2003). Fragmentation affects the mating system of these species by creating genetic bottlenecks (Aldrich and Hamrick, 1998), decreasing offspring fitness (Cascante et al, 2002), or by reducing the number of sires (Fuchs et al, 2003). These tropical species are usually animal-pollinated and occur at naturally low densities. The mutualistic relationship between trees and pollinators may make these species more susceptible to habitat fragmentation than wind-pollinated species. Nevertheless, in wind-pollinated conifers, the mating system can be affected by population structure attributes. For example, in some conifer species, outcrossing rates are correlated with population density (Farris and Mitton, 1984; Rajora et al, 2002), family structure and tree heights (Mitton, 1992; O'Connell et al, 2004). In wind-pollinated trees, surrounding vegetation can also impede pollen dispersal, so that fragmentation can increase pollen and gene flow distances between forest trees (Young and Merriam, 1994; Dyer and Sork, 2001).

White spruce (Picea glauca (Moench) Voss), is an ecologically and economically important conifer with a trans-continental range in Canada (Nienstaedt and 
Zasada, 1990). Although white spruce is widespread in Canada, there are concerns about the impact of harvesting and fragmentation on its genetic resources (Rajora, 1999). Natural populations of white spruce have moderate to high levels of genetic diversity (Cheliak et al, 1985; Innes and Ringius, 1990; Furnier et al, 1991; Rajora, 1999; Rajora and Dancik, 2000). White spruce is a predominantly outcrossing species, but does show significant amounts of self-fertilization in some populations. Population outcrossing rates of $98 \%$ (Cheliak et al, 1985) and 93\% (Denti and Schoen, 1988) have been measured for Ontario populations, but rates as low as 70 and $76 \%$ have been estimated for two Newfoundland populations (Innes and Ringius, 1990). Individual family outcrossing rates range from 78 to $100 \%$ (Denti and Schoen, 1988). White spruce shows high inbreeding depression, with 80-96\% lower seed set following self-pollination compared to cross-pollinations (Fowler and Park, 1983). We have previously found that forest fragmentation negatively affects reproductive success in white spruce, by reducing the number of fertilized ovules and viable seeds per cone in small stands ( $\mathrm{O}^{\prime}$ Connell et al, 2006). Trees from small stands ( $<10$ trees) set $38 \%$ fewer seeds per cone than trees from large stands ( $>100$ trees). The seed viability data strongly suggest that pollen-limitation and increased inbreeding in small stands limit seed set in fragmented stands of white spruce.

Outcrossing rates in plants are usually estimated from filled seeds, and more often from germinated seeds or seedlings. In most conifers, self-fertilized embryos result in empty seeds. Most inbred individuals are eliminated at very early, postzygotic stages of development (eg during embryo development); therefore, the outcrossing estimates based on molecular marker data alone will be inflated compared to actual cross-fertilization rates. By combining empty seed data with molecular marker based estimates of selfing, we can obtain the primary selfing rate, which is the selfing rate at the ovule fertilization stage (ie actual inbreeding rate; Rajora et al, 2000a, 2002).

In this study, we used allozyme markers in addition to seed set data, to assess the genetic impacts of forest fragmentation on natural stands of white spruce at the landscape level. Specifically, the objectives were to determine the effects of stand size on the levels of genetic diversity and structure of the pollen pool, inbreeding and correlated matings in the mature parental stands, and genetic (allelic and genotypic) diversity of the resulting filial (seed) population.

\section{Materials and methods}

\section{Study site and sampling}

The study area is located at the western end of Lake Nipissing, Northern Ontario, Canada (O'Connell et al, 2006). The area around Lake Nipissing offers an ideal site to study the impacts of habitat fragmentation on temperate, wind-pollinated species. This area is an old glacial lakebed, interspersed with a number of rocky outcrops of varying sizes, containing residual forests composed, for the most part, of white spruce, eastern white pine (Pinus strobus L.), white birch (Betula papyrifera Marsh.), and trembling aspen (Populus tremuloides Michx.). These isolated patches of trees occur within an agricultural landscape used largely for corn and dairy production. Small tree stands also occur on islands in Lake Nipissing.

We sampled 23 white spruce stands during August and September 1994. The location map of the stands and details on the sampling procedure are provided in O'Connell et al (2006). Briefly, we sampled cones from a total of 104 trees, from 23 stands, varying in size from a single reproductive tree to contiguous forest with thousands of individuals (Table 1). Sampled stands were divided into three stand size classes (SSCs) that differed by an order of magnitude: small ( $1-<10$ trees), medium (10- $<100$ trees) and large ( $\geq 100$ trees). The total sample area was $378 \mathrm{~km}^{2}$. Sampled stands were separated by $250-3000 \mathrm{~m}$ from the closest other neighboring white spruce stand (Table 1). Our previous study showed that even at the lowest of these inter-stand distances, seed production was significantly reduced in small stands (O'Connell et al, 2006). Sampled trees ranged in age from 19 to 73 years, and in height from 4 to $22 \mathrm{~m}$. Trees did not differ significantly in age and size among SSCs (O'Connell et al, 2006). In all 19 stands occurred on rocky outcrops surrounded by agricultural fields, and four stands occurred on similar rocky outcrops on small islands in the lake (A, B, C, and D; Table 1). We sampled cones from all reproductive individuals in small stands, and from six trees per stand in the medium and large stand size classes. There was no significant difference in white spruce tree density among the three SSCs (O'Connell et al, 2006).

\section{Genotyping}

Seeds were hydrated in Petri dishes on filter paper moistened with distilled water for at least $24 \mathrm{~h}$ prior to dissection. A total of 96 embryos were assayed for each family (ie seeds from the same maternal tree), except for two trees from stand C, where only 52 and 36 seeds were available. Of these sampled embryos, the corresponding megagametophytes were assayed separately for 10 seeds per family. Megagametophytes in conifers have the same haploid genotype as the female gamete. Individual embryos and megagametophytes were homogenized in $10 \mu \mathrm{l}$ of cold seed extraction buffer (Cheliak and Pitel, 1984). Enzyme electrophoresis was performed using fresh extracts on cellulose acetate gels (Helena Laboratories, Beaumont, TX) following Hebert and Beaton (1989). All gels were run for $25 \mathrm{~min}$ at $200 \mathrm{~V}$. Based on a prescreening of enzyme systems and encoding allozyme loci, six polymorphic loci from four enzyme systems were used in this study. These loci met the suitability criteria for mating system analysis. The four enzyme systems assayed were: Furmarate hydratase or Fumarase (FUM; EC 4.2.1.2), Isocitrate dehydrogenase (IDH; EC 1.1.1.42), Leucine aminopeptidase (LAP; EC 3.4.11.1), and Phosphoglucomutase (PGM; EC 5.4.2.2). The six allozyme loci used for mating system and genetic diversity analyses are as follows: Fum1, Idh1, Lap1, Lap2, Pgm1, and Pgm2. A total of 9880 embryos, and corresponding megagametophytes for 1030 of these embryos, from 104 families were genotyped (Supplementary Table 1). The segregation of the two most common alleles for each locus was verified in megagametophytes of heterozygous mother trees, and they all showed single-locus Mendelian segregation patterns. 
Table 1 Stand parameters, sample sizes and percent outcrossing $\left(t_{m}\right.$, multilocus and $t_{s}$, mean single-locus) estimates and percent bi-parental inbreeding $\left(t_{m}-t_{s}\right)$ in 23 stands of white spruce in Northern Ontario, Canada

\begin{tabular}{|c|c|c|c|c|c|c|}
\hline Stand & $\begin{array}{l}\text { No. of reproductive } \\
\text { trees per stand }\end{array}$ & $\begin{array}{l}\text { Distance to nearest } \\
\text { stand }(\mathrm{m})\end{array}$ & $\begin{array}{l}\text { No. of embryos } \\
\text { sampled }\end{array}$ & $\mathrm{t}_{m}(S D)$ & $\mathbf{t}_{s}(S D)$ & $\mathrm{t}_{m}-\mathrm{t}_{s}(S D)$ \\
\hline \multicolumn{7}{|l|}{ Small } \\
\hline A & 3 & 400 & 288 & $89.5(0.8)$ & $89.8(0.2)$ & $-0.3(0.7)$ \\
\hline B & 1 & 2000 & 96 & $90.8(0.7)$ & $90.2(0.2)$ & $0.6(0.5)$ \\
\hline $\mathrm{C}$ & 3 & 3000 & 183 & $91.8(1.2)$ & $90.2(0.2)$ & $1.6(1.0)$ \\
\hline D & 3 & 1500 & 288 & $90.4(0.6)$ & $90.0(0.1)$ & $0.4(0.5)$ \\
\hline $\mathrm{E}$ & 1 & 300 & 96 & $90.3(0.6)$ & $90.0(0.2)$ & $0.3(0.5)$ \\
\hline F & 4 & 300 & 384 & $90.7(0.9)$ & $90.1(0.2)$ & $0.6(0.8)$ \\
\hline G & 1 & 700 & 96 & $90.4(0.4)$ & $90.0(0.1)$ & $0.4(0.3)$ \\
\hline $\mathrm{H}$ & 3 & 500 & 288 & $90.4(0.6)$ & $90.0(0.1)$ & $0.4(0.5)$ \\
\hline I & 1 & 250 & 96 & $89.4(0.7)$ & $89.9(0.1)$ & $-0.5(0.6)$ \\
\hline $\mathrm{J}$ & 8 & 300 & 768 & $89.2(1.2)$ & $89.7(0.4)$ & $-0.5(0.9)$ \\
\hline K & 4 & 250 & 384 & $91.1(1.1)$ & $90.2(0.3)$ & $0.9(0.8)$ \\
\hline \multicolumn{7}{|c|}{ Medium } \\
\hline $\mathrm{L}$ & 21 & 300 & 576 & $89.5(0.7)$ & $89.8(0.2)$ & $-0.3(0.6)$ \\
\hline M & 20 & 250 & 576 & $90.3(0.5)$ & $89.9(0.2)$ & $0.4(0.5)$ \\
\hline $\mathrm{N}$ & 56 & 450 & 576 & $91.0(0.9)$ & $90.2(0.3)$ & $0.8(0.7)$ \\
\hline $\mathrm{O}$ & 43 & 300 & 576 & $91.8(1.0)$ & $90.2(0.3)$ & $1.6(0.8)$ \\
\hline $\mathrm{P}$ & 56 & 300 & 576 & $89.9(0.8)$ & $90.0(0.2)$ & $-0.1(0.6)$ \\
\hline Q & 20 & 300 & 576 & $92.0(1.3)$ & $90.4(0.5)$ & $1.6(0.8)$ \\
\hline \multicolumn{7}{|l|}{ Large } \\
\hline $\mathrm{R}$ & 100 & 400 & 576 & $91.8(1.0)$ & $90.1(0.2)$ & $1.7(0.8)$ \\
\hline $\mathrm{S}$ & 180 & 400 & 576 & $89.6(0.8)$ & $89.9(0.2)$ & $-0.3(0.7)$ \\
\hline $\mathrm{T}$ & 180 & 300 & 576 & $90.6(0.8)$ & $90.0(0.1)$ & $0.6(0.7)$ \\
\hline U & $>500$ & Contiguous & 576 & $91.8(1.1)$ & $90.3(0.3)$ & $1.5(0.9)$ \\
\hline V & $>500$ & Contiguous & 576 & $91.7(1.2)$ & $90.2(0.3)$ & $1.5(0.9)$ \\
\hline W & $>500$ & Contiguous & 576 & $92.4(0.9)$ & $90.2(0.3)$ & $2.2(0.7)$ \\
\hline
\end{tabular}

Every reproductive tree was sampled in small stands, and six trees per stand were sampled in medium-sized and large stands.

Ovule and pollen pool genetic heterogeneity

Differentiation among the 23 stands for maternal allele frequencies ( $n=104$ trees) were tested with a multivariate analysis of molecular variance (AMOVA) (Dyer and Sork, 2001). The allele frequencies of the pollen pools are estimates of the frequency of the paternal alleles in the sampled seeds from individual families or stands, respectively. To test for allele frequency heterogeneity in the pollen pool among stands, and among families nested within stands, we used the program TwoGener (Smouse et al, 2001). TwoGener estimates $\Phi_{\mathrm{FT}}$, a measure of pollen pool differentiation among maternal trees (ie families). This measure is analogous to $F_{\mathrm{ST}}$ in an AMOVA, but instead of estimating differentiation among populations, it estimates the amount of differentiation in the pollen pool among different mothers. We conducted a two level-analysis of the pollen pool with TwoGener. The effects analyzed were stand $(N=23)$, and family $(N=104)$, nested within stand. The number of families per stand ranged from one to six (mean of 2.9).

We also used TwoGener to obtain pairwise estimates of genetic differentiation in the pollen pools among the 23 stands. The R-Package (version 4; Casgrain and Legendre, 2001) was used to convert stand $x-y$ coordinates in meters, to pairwise distances in meters. To test for a correlation between genetic differentiation and geographic distances between stands, we used a Mantel's test (Mantel, 1967).

\section{Mating system analysis}

Multilocus $\left(t_{\mathrm{m}}\right)$ and mean single-locus $\left(t_{\mathrm{s}}\right)$ outcrossing rates were jointly estimated with pollen gene frequencies using the program MLTR (version 3.0; Ritland, 2002) and the Expectation-Maximization method. The pollen pool allele frequencies within a stand were more similar to the overall ovule frequencies, than the ovule allele frequencies within the same stand (results not shown). The TwoGener analysis also indicated that there was no significant differentiation in the pollen pool among mothers, or among stands. Mating system parameters for each group were, therefore, analyzed using the pooled data for all stands. Analyzing the pooled data increases the statistical power (Ritland, 2002). Outcrossing rates were estimated at four different levels: (1) grouped as individual families (ie maternal tree), (2) grouped by stand, (3) as a single pooled population of all stands, and (4) grouped by SSC. SD and 95\% confidence intervals for the mating system parameter estimates were obtained from 300 bootstraps with resampling individuals within families for the family and stand level estimates, and resampling of families for the pooled population of all stands and SSC level estimates. Correlation of paternity $\left(r_{\mathrm{p}}\right)$, correlation of outcrossing $\left(r_{\mathrm{t}}\right)$ and inbreeding coefficients $(F)$ estimates were constrained to equal zero when estimating the outcrossing rates. We also estimated $r_{p}$ (the probability that two outcrossed seeds from a family share the same father) with the outcrossing rate fixed at $94 \%$, and $F$ and $r_{\mathrm{t}}$ fixed at zero. Biparental inbreeding rates were estimated as $t_{\mathrm{m}}-t_{\mathrm{s}}$. Significant differences in outcrossing estimates $\left(t_{\mathrm{m}}\right.$ and $\left.t_{\mathrm{s}}\right)$, biparental inbreeding $\left(t_{\mathrm{m}}-t_{\mathrm{s}}\right)$ and $r_{p}$ between SSCs were tested using MLTR. Mating system estimates were considered as significantly different from each other when their $95 \%$ confidence intervals did not overlap. 
The effective number of pollen parents, $N_{\mathrm{ep}}$, can be estimated from both the correlation of paternity estimate $\left(r_{\mathrm{p}}\right)$ and the estimate of differentiation among families $\left(\Phi_{\mathrm{FT}}\right)$. Both, $\left[N_{\mathrm{ep}}\right]^{-1}$ and $r_{\mathrm{p}}$ are defined as the probability that two pollen grains drawn from the same female are from the same male, thus $N_{\mathrm{ep}}=r_{\mathrm{p}}^{-1}$ (Ritland, 1989; Smouse and Sork, 2004). In the absence of inbreeding, $2 \Phi_{\mathrm{FT}}$ should approximate $r_{\mathrm{p}}$ and thus, $N_{\mathrm{ep}} \approx\left(2 \Phi_{\mathrm{FT}}\right)^{-1}$ (Austerlitz and Smouse, 2001; Burczyk and Koralewski, 2005). We estimated $N_{\mathrm{ep}}$ from $r_{\mathrm{p}}$ as well as from $\Phi_{\mathrm{FT}}$, calculated first for a single pooled population of all stands, and then separately for the small, medium, and large SSCs.

We estimated the primary selfing rate, by combining empty seed data with allozyme-based estimates of selfing in the filled seeds. In white spruce, seed development requires pollination and fertilization (Owens and Molder, 1979). Empty seeds (postzygotic abortions) have rounded seed coats with an aborted embryo (O'Connell et al, 2006). Inbreeding depression is the major cause for embryo abortion in conifers. As discussed in Rajora et al (2000a, 2002), we assumed that the $80 \%$ of the empty seeds were caused by inbreeding depression following self-fertilization and $20 \%$ by environmental factors. Estimates of the percentage of empty seeds were based on 25 cones/per tree (when available) for each of 102 trees (O'Connell et al, 2006). The primary selfing rate for each of the 102 trees was calculated by using the following formula for actual inbreeding rate from Rajora et al (2000a, 2002) where the primary selfing rate $=$ (percentage of empty seeds $\times$ $80 \%)+($ percentage of filled seeds $\times s)$, where $s$ is the selfing rate and $s=1-t_{\mathrm{m}}$, where $t_{\mathrm{m}}$ is the individual family outcrossing rate estimated with allozymes. To test for an effect of SSC on the percentage of empty seeds, the percentage of selfed seeds and the primary selfing rates, we used a nested ANOVA, with SSC as a fixed effect, and stand, nested within SSC, as a random effect. We performed posthoc contrast tests to test for significant pairwise differences among SSC. We conducted all statistical analyses with the software $\mathrm{JMP}^{\mathrm{TM}}$ (version 3.2.1, SAS Institute, 1997).

A Pearson correlation analysis was used to determine if there was a positive correlation between individual family multilocus selfing rates $\left(s=1-t_{\mathrm{m}}\right)$, and the percentage of empty seeds. Data for both these measures were available for 102 of the 104 trees.

\section{Genetic diversity analyses}

Measures of genetic diversity were estimated separately for the filial (ie seed) population of each stand. Sample sizes ranged from one to six families (96 to 576 seeds) per stand, with the exception of one small stand, where 768 embryos from eight trees were genotyped. For each stand, we calculated both allelic and genotypic measures of genetic diversity. We estimated expected heterozygosity $(\mathrm{He})$, observed heterozygosity $(\mathrm{Ho})$, and Weir and Cockerham's (1984) inbreeding coefficient $(f)$ with the software Genepop (version 3.3, an updated version of 1.2, Raymond and Rousset, 1995). We also calculated the number of alleles per locus $(A)$, and the effective number of alleles per locus as:

$$
A e=\frac{1}{1-H e}
$$

where $1-H e$ is the expected homozygosity. The program FSTAT (Goudet, 2001) estimates genetic measures that are corrected for samples of different sizes, and thus allows us to compare these quantities among populations. We used FSTAT to calculate the allelic richness $(A R)$, the gene diversity $(H$, equivalent to $H e)$ and the inbreeding coefficient $\left(F_{\mathrm{IS}}\right)$.

We also calculated latent genetic potential (LGP; Bergmann et al, 1990) and a measure of genotypic diversity, genotypic additivity $\left(G_{\mathrm{A}}\right.$; Rajora et al, 2000b), for each stand. The latent genetic potential provides an estimate of new mutations and rare or low frequency allele complement that could provide selection potential for adaptation under changed environment and stress conditions (Stebbins and Hartl, 1988). LGP was calculated as the difference between total number of alleles and effective number of alleles summed over all loci:

$$
L G P=\sum_{l=1}^{n}\left(A_{l}-A e_{l}\right)
$$

where $l$ is equal to locus 1 to $n, A$ is the number of alleles and $A e$ is the number of effective alleles at locus $l$. Genotypic additivity $\left(G_{\mathrm{A}}\right)$ estimates are the measures of genotypic diversity reflecting the diversity of allele combinations in diploid genomes. $G_{A}$ is the observed or theoretical number of single-locus genotypes $(G)$ summed over all loci. Observed $\left[G_{A}(O)\right]$ and expected $\left[G_{\mathrm{A}}(E)\right]$ genotypic additivity were calculated as:

$$
G_{\mathrm{A}}(O)=\sum_{l=1}^{n} G(O) \text { and } G_{\mathrm{A}}(E)=\sum_{l=1}^{n} G(E)
$$

where $l$ is equal to locus 1 to $n, G(O)$ is the number of genotypes observed at locus $l$, and

$$
G(E)=\frac{a(a+1)}{2}
$$

where $a$ is the number of alleles at locus $l$. As these measures are sensitive to sample size, samples from small stands will likely show lower diversity simply due to smaller sample sizes. One to four families and 96 to 384 seeds per stand were sampled in small stands (except for one stand where eight families and 768 embryos were sampled), versus six families and 576 seeds per stand sampled in the medium-sized and large stands. These measures $\left(A, L G P, G_{\mathrm{A}}(O)\right.$ and $\left.G_{\mathrm{A}}(E)\right)$ can be statistically compared, however, between medium-sized and large stands, because the sample size is identical in both of these SSCs ( $n=576$ seeds per stand). For each measure of genetic diversity, a one-way ANOVA was used to test for differences in stand measures of genetic diversity among SSCs. We performed two analyses for $A, L G P, G_{A}(O)$ and $G_{\mathrm{A}}(E)$, one including small stands and one excluding small stands.

\section{Outcross pollen pool genetic diversity}

We estimated the allele frequency of the outcross pollen pool separately for each of the 23 stands using MLTR with the outcrossing rate fixed at $94 \%$. The pollen genetic diversity $\left(H_{\text {(pollen) }}\right)$ and allelic richness $\left(A R_{\text {(pollen) }}\right)$ of the 23 stands were estimated at each locus with the program FSTAT. We tested for a significant difference in mean stand-level pollen gene diversity and allelic richness among the three SSCs using a permutation test in FSTAT. 


\section{Results}

Ovule and pollen pool heterogeneity

An AMOVA indicated significant differences in ovule allele frequencies among the 23 stands $\left(F_{\mathrm{ST}}=7.4 \%\right.$; $P=0.01)$. The TwoGener estimates of pollen pool differentiation among stands $\left(\Phi_{\mathrm{ST}}=-0.01\right)$, and families nested within stands $\left(\Phi_{\mathrm{FS}}=-0.015\right)$ were very near zero, indicating that there was no genetic structure in the pollen pool. The estimate of the percent variation due to within family differences was $>100 \%(102.6 \%)$. Estimates of $\Phi$-values below zero and percent variation above $100 \%$ are statistical artifacts due to sampling error, but can be expected when there is little or no pollen pool structure. There was also no significant correlation between pairwise estimates of genetic differentiation in the pollen pool among stands, and geographic distances between stands $(n=253$, Mantel's $r=-0.154, P=0.084$, based on 1000 permutations).

\section{Mating system}

Outcrossing rates at the stand level had quite a narrow range. Multilocus outcrossing rates, $t_{\mathrm{m}}$, ranged from 89.2 to $92.4 \%$, and mean single locus outcrossing rates, $t_{\mathrm{s}}$, ranged from 89.7 to $90.3 \%$ (Table 1). Estimates of biparental inbreeding were low and ranged from -0.5 to $2.2 \%$. The overall multilocus outcrossing rate estimated for the pooled stands was high $(n=104$ families; $\left.t_{\mathrm{m}}=93.8 \%\right)$ and the mean single locus outcrossing rate was slightly lower $\left(t_{\mathrm{s}}=90.6 \%\right)$. Both $t_{\mathrm{m}}$ and $t_{\mathrm{s}}$ estimates were significantly different from unity (Table 2). The biparental inbreeding estimate $\left(t_{\mathrm{m}}-t_{\mathrm{s}}=3.2 \%\right)$ was significantly greater than zero.

When mating system parameters were estimated by SSC (small, medium or large), there were no significant differences among groups in multilocus outcrossing rates $\left(t_{\mathrm{m}}\right)$, single locus outcrossing rates $\left(t_{\mathrm{s}}\right)$ and biparental inbreeding rates $\left(t_{\mathrm{m}}-t_{\mathrm{s}}\right)$ (Table 2). All SSCs showed amounts of selfing and biparental inbreeding that were significantly greater than zero. Correlation of paternity estimates were small for all SSCs. However, small stands had a slightly, but significantly, higher estimate of correlation of paternity (1.6\%) than large and mediumsized stands (both $0.7 \%$ ).

Based on the $r_{\mathrm{p}}$ values, the estimated effective population size $\left(N_{\mathrm{ep}}\right)$ was 62.5 trees for small stands and 143 trees each for the medium-sized and large stands. The TwoGener analysis yielded negative $\Phi_{\mathrm{FT}}$ values for small and large stands, and thus we could not calculate a $N_{\mathrm{ep}}$ estimate from these values. When values of $\Phi_{\mathrm{FT}}$ are near zero, then $N$ is very large. In mediumsized stands, there was low, but significant differentiation among pools from different families $\left(\Phi_{\mathrm{FT}}=2.6 \%\right)$. The $N_{\mathrm{ep}}$ for medium-sized stands estimated as $\left(2 \Phi_{\mathrm{FT}}\right)^{-1}=29$, was much lower than when estimated as $r_{\mathrm{p}}^{-1}=142$.

\section{Primary selfing rates}

Trees in the medium SSC had a significantly higher proportion of empty seeds than the large SSC (Table 3). At the individual family-level, the allozyme-based estimates of selfing ranged between 6.8 and $13 \%$ (mean $=9.6 \pm 1.3 \% \mathrm{SD}$ ), and the mean estimate of primary selfing over all trees was $39.5 \%( \pm 10.7 \%$ SD). Mean family level estimates of selfing did not differ among SSCs, but the primary selfing rates were significantly higher in medium stands than in large stands (Table 3). The proportion of empty seeds and selfing rates were both lowest in the large stands, but these two measures were not significantly correlated $(n=102$ trees, Pearson's $r=0.102 ; P=0.31)$.

\section{Genetic diversity}

The six variable loci (Fum1, Idh1, Lap1, Lap2, Pgm1, and Pgm2) showed high levels of allelic diversity. In the filial subpopulation (ie seeds) we detected a total of 26 alleles,

Table 2 Mating system parameter estimates for all 23 stands pooled in one populations, and separately for small, medium and large stands of white spruce

\begin{tabular}{|c|c|c|c|c|c|c|c|c|}
\hline Group & $\mathrm{N}$ & $\mathrm{t}_{m}(S D)$ & $\mathrm{t}_{s}(S D)$ & $\mathbf{t}_{m}-\mathbf{t}_{s}(S D)$ & $\mathrm{r}_{\mathrm{p}}(S D)$ & $\mathrm{N}_{e p}$ & $\Phi_{F T}$ (P-value) & $\mathrm{N}_{e p}$ \\
\hline Pooled stands & 104 & $93.8^{*}(0.8)$ & $90.6^{*}(0.7)$ & $3.2^{\dagger}(0.5)$ & $0.010^{\dagger}(0.001)$ & 100 & $-0.025(1.00)$ & - \\
\hline Small & 32 & $94.5^{\mathrm{a}, *}(1.4)$ & $90.5^{\mathrm{a}, *}(0.7)$ & $4.0^{\mathrm{a}, \dagger}(0.8)$ & $0.016^{\mathrm{a}, \dagger}(0.002)$ & 62.5 & $-0.055(1.00)$ & - \\
\hline Medium & 36 & $92.7^{\mathrm{a}, *}(1.4)$ & $90.5^{\mathrm{a}, *}(0.7)$ & $2.1^{\mathrm{a}, \dagger}(0.9)$ & $0.007^{\mathrm{b}, \dagger}(0.001)$ & 142.9 & $0.026^{\dagger}(0.01)$ & 19 \\
\hline Large & 36 & $95.3^{a, *}(1.0)$ & $91.2^{\mathrm{a}, *}(0.6)$ & $4.1^{\mathrm{a}, \dagger}(0.6)$ & $0.007^{\mathrm{b}, \dagger}(0.001)$ & 142.9 & $-0.017(1.00)$ & - \\
\hline
\end{tabular}

Note: mating system estimates are not means but estimated simultaneously for all trees within a group.

$N$, number of families sampled. Multilocus estimate of the percentage of outcrossed seeds $\left(t_{\mathrm{m}}\right)$, mean single-locus estimate of the percentage of outcrossed seeds $\left(t_{\mathrm{s}}\right)$, percentage of biparental inbreeding $\left(t_{\mathrm{m}}-t_{\mathrm{s}}\right)$, correlation of paternity $\left(r_{\mathrm{p}}\right)$, pollen pool differentiation among families $\left(\Phi_{\mathrm{FT}}\right)$, and the effective number of pollen donors $\left(N_{\mathrm{ep}}\right)$ estimated both from $r_{\mathrm{p}}$ and $\Phi_{\mathrm{FT}}$.

*Significantly $<100 \%$, 'Significantly $>0 \%$; Estimates in a column followed by the same superscript letters are not significantly different.

Table 3 The effect of stand size class (SSC) and Stand (nested within SSC) on mean percentage of empty seeds, percentage self-fertilized seeds and percentage of primary selfing in 11 small, 6 medium and 6 large stands of white spruce

\begin{tabular}{|c|c|c|c|c|c|}
\hline \multirow[b]{2}{*}{ No. families sampled } & \multicolumn{3}{|c|}{ SSC } & \multicolumn{2}{|c|}{ ANOVA-effect } \\
\hline & $\begin{array}{c}\text { Small } \\
30\end{array}$ & $\begin{array}{l}\text { Medium } \\
\quad 36\end{array}$ & $\begin{array}{l}\text { Large } \\
36\end{array}$ & $\begin{array}{c}\text { SSC } 2 d f \\
\text { F-ratio (P-value) }\end{array}$ & $\begin{array}{l}\text { Stand (SSC) } 20 d f \\
\text { F-ratio (P-value) }\end{array}$ \\
\hline \% empty seeds (SE) & $44.4^{\mathrm{a}, \mathrm{b}}(2.5)$ & $48.8^{\mathrm{a}}(2.3)$ & $34.6^{\mathrm{b}}(2.3)$ & $5.28(0.01)$ & $2.48(0.002)$ \\
\hline$\%$ selfing (SE) & $9.7^{\mathrm{a}}(2.4)$ & $9.7^{\mathrm{a}}(2.2)$ & $9.4^{\mathrm{a}}(2.2)$ & $0.55(0.59)$ & $0.88(0.61)$ \\
\hline$\%$ primary selfing (SE) & $40.9^{\mathrm{a}, \mathrm{b}}(1.8)$ & $44.0^{\mathrm{a}}(1.6)$ & $33.9^{b}(1.6)$ & $5.56(0.012)$ & $2.16(0.0084)$ \\
\hline
\end{tabular}

Means in a row followed by the same superscript letters are not significantly different. 
Table 4 Genetic diversity measures of filial populations from 23 stands of white spruce grouped into three stand size classes (SSC): small, medium and large stands

\begin{tabular}{|c|c|c|c|c|c|c|c|c|c|c|c|c|}
\hline SSC & $\mathrm{N}$ & $\mathrm{He}$ & Ho & $\mathrm{f}$ & A & $\mathrm{Ae}$ & $\mathrm{AR}$ & $\mathrm{H}$ & $\mathrm{F}_{I S}$ & LGP & $\mathrm{G}_{A}(\mathrm{O})$ & $\mathrm{G}_{A}(\mathrm{E})$ \\
\hline Small & 11 & 0.329 & 0.331 & -0.005 & 2.77 & 1.57 & 2.16 & 0.361 & 0.003 & 7.20 & 22 & 33.2 \\
\hline Medium & 6 & 0.368 & 0.364 & 0.011 & 3.31 & 1.65 & 2.06 & 0.311 & 0.015 & 9.91 & 30 & 45 \\
\hline Large & 6 & 0.345 & 0.339 & 0.016 & 3.22 & 1.59 & 2.19 & 0.343 & -0.003 & 9.80 & 30 & 43.6 \\
\hline Mean over all populations & 23 & 0.344 & 0.342 & 0.004 & 3.03 & 1.60 & 2.14 & 0.343 & 0.002 & 8.59 & 26.3 & 39 \\
\hline \multicolumn{13}{|l|}{ ANOVA (Among SSC) } \\
\hline All stands $F_{[2,22]}$ & & 1.49 & 0.92 & 0.77 & 5.80 & 1.11 & 2.67 & 2.67 & 0.19 & 5.13 & 11.70 & 6.12 \\
\hline$P$-value & & 0.25 & 0.41 & 0.77 & 0.01 & 0.35 & 0.09 & 0.10 & 0.83 & 0.02 & 0.0004 & 0.008 \\
\hline Large \& med. $\mathrm{F}_{[1,11]}$ & & & & & 0.29 & & & & & 0.02 & 0.04 & 0.73 \\
\hline$P$-value & & & & & 0.60 & & & & & 0.90 & 0.80 & 0.70 \\
\hline
\end{tabular}

$N$, number of stands; $H e$, mean expected heterozygosity; Ho, mean observed heterozygosity; $f$, multilocus inbreeding coefficient; $A$, mean number of alleles per locus; $A$ e, number of effective alleles per locus; $A R$, mean allelic richness adjusted for sample size; $H$, mean $H e$ adjusted for sample size; $F_{\mathrm{IS}}$, multilocus inbreeding coefficient adjusted for sample size; $L G P$, latent genetic potential; $G_{\mathrm{A}}(O)$, genotypic additivity observed; $G_{\mathrm{A}}(E)$, genotypic additivity expected.

Table 5 Estimates of pollen genetic diversity at the stand level at six allozyme loci in 23 white spruce stands

\begin{tabular}{lcccc}
\hline & \multicolumn{3}{c}{ SSC } & P-value \\
\cline { 2 - 4 } & $\begin{array}{c}\text { Small } \\
\mathrm{N}=11\end{array}$ & $\begin{array}{c}\text { Medium } \\
\mathrm{N}=6\end{array}$ & $\begin{array}{c}\text { Large } \\
\mathrm{N}=6\end{array}$ & \\
\hline Mean $A / L_{\text {(pollen) }}$ & 2.790 & 3.361 & 3.250 & \\
Mean $A R_{\text {(pollen) }}$ & 2.188 & 2.217 & 2.247 & 0.55 \\
Locus & & & & \\
Fum1 & & $H_{\text {(pollen) }}$ & & \\
Idh1 & 0.220 & 0.228 & 0.173 & \\
Lap1 & 0.404 & 0.457 & 0.432 & \\
Lap2 & 0.247 & 0.238 & 0.266 & \\
Pgm1 & 0.274 & 0.263 & 0.269 & \\
Pgm2 & 0.518 & 0.504 & 0.510 & \\
Mean $H_{\text {(pollen) }}$ & 0.454 & 0.501 & 0.500 & \\
\hline
\end{tabular}

Two-sided $P$-values of differentiation among stand size classes (SSC) were obtained from 100 permutations.

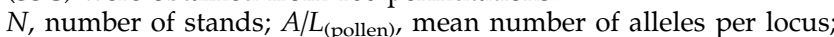

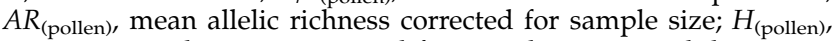
mean genetic diversity corrected for sample size at each locus.

and the number of alleles per locus ranged between three and five with a mean of 4.3 alleles per locus. The measures of genetic diversity of the filial populations from 23 white spruce stands are in Table 4 (details provided in Supplementary Table 2). Stand level genetic diversity in the filial generation measured by $\mathrm{He}, \mathrm{Ho}$, and Ae did not differ significantly among the SSCs. There was also no significant difference in the inbreeding coefficient, $f$, among SSCs. Measures of genetic diversity that are sensitive to the sample size, such as $A, L G P, G_{\mathrm{A}}(O)$, $G_{\mathrm{A}}(E)$, were all slightly higher in medium-sized stands, but were not significantly different from those in larger stands (Table 4). All four measures, however, were significantly lower in small stands due to the smaller number of seeds sampled per stand, and to the lower number of families present in these stands.

\section{Outcross pollen pool genetic diversity}

We found no significant difference in pollen diversity among the three SSCs. Although we detected fewer alleles in the pollen pool of small stands, there was no significant difference in either gene diversity, $H_{\text {(pollen) }}$ or allelic richness, $\mathrm{AR}_{\text {(pollen) }}$ among the SSCs (Table 5). The significant difference in the number of alleles among SSC is likely due to the smaller sample sizes in the small stands, where as few as 96 embryos were sampled in some small stands (Table 1). Gene diversity and allelic richness measures were both corrected for differences in sample sizes.

\section{Discussion}

\section{Pollen pool differentiation}

Overall, there were no genetic differences in the pollen pool among stands or families of white spruce in the studied fragmented landscape, despite the significant difference in ovule allele frequencies among stands. This result is particularly striking in stands where every reproductive tree was sampled and, therefore, every genotype is known. The pollen pool allele frequency in these stands does not reflect the locally available pollen pool, suggesting that a large proportion of the pollen comes from the surrounding trees outside the stands. The lack of pollen pool differentiation can explain the lack of differentiation in mating system parameters among SSCs and levels of genetic diversity among the filial populations from different SSCs.

\section{Outcrossing and inbreeding rates}

Despite the large range of stand sizes sampled (single trees to contiguous forest with $>500$ white spruce trees) and the large inter-stand distances (up to $3 \mathrm{~km}$ ), no effect of stand size on the outcrossing rates of white spruce was detected from the molecular marker data alone. The high outcrossing rates (overall $t_{\mathrm{m}}=93.8 \%$ and mean $t_{\mathrm{s}}=90.6 \%$ ) observed in our study were similar to previously reported rates for white spruce by Denti and Schoen (1988; mean $t_{\mathrm{s}}=93.1 \%$ ) and Cheliak et al (1985; mean $\left.t_{\mathrm{s}}=98 \%\right)$. Although self-fertilization $(6.2 \%)$ and biparental inbreeding $(3.2 \%)$ were significantly greater than zero, these values were not significantly different among SSCs. There were also no significant differences in inbreeding coefficients of the filial populations from the small, medium-sized, and large stands.

Results from previous studies in tropical trees (eg Fuchs et al, 2003) do show a trend towards higher inbreeding in fragmented stands. However, these results are not statistically significant. Other, studies of tropical forest trees mating systems have also failed to find a 
significant effect of forest fragmentation on levels of inbreeding in forest tree populations based on molecular marker data alone (Hall et al, 1996; Young et al, 1996). In contrast to previous mating system studies in fragmented populations, we sampled a large number of embryos ( $\sim 10000)$ and obtained small standard errors $(<2 \%)$ for the mating system estimates; thus providing more precise mating system estimates for white spruce. Given the large sample sizes of both seeds and populations in this study, the failure to detect an effect of fragmentation is unlikely to be due to low power and represent type II statistical errors. Rather our study provides strong evidence that there is no genetic effect of fragmentation in this species.

Nevertheless, failing to detect inbreeding differences in trees among different size stands using molecular data does not mean that fragmentation does not increase inbreeding. As many tropical trees are self-incompatible, and trees in general, including temperate conifers, have high levels of early inbreeding depression, most inbred embryos are eliminated before they can be sampled with molecular markers. Thus, viable assayed seeds may show high levels of outcrossing even when high rates of self-pollination or self-fertilization have occurred. This seems to be case in our study where small and mediumsized stands had a higher proportion of empty seeds (aborted embryos) than large stands, and the estimated primary selfing rates in the medium-sized stands were significantly greater than in large stands. Selfing estimates based on the empty seed data followed the same pattern as allozyme-based selfing estimates, where the lowest estimates of selfing were found in large stands. However, there was no correlation between the two measures at the individual tree level. The lack of correlation between the seed viability and allozymebased selfing estimates is due to individual tree differences for inbreeding depression and possibly also micro environmental conditions.

\section{Effective number of pollen parents $\left(N_{\mathrm{ep}}\right)$}

In our study, we observed high estimates for the effective number of pollen parents in white spruce. Theses results are consistent with the general trend observed in other conifer species. Based on $N_{\text {ep }}$ estimates from 19 different studies of forest trees, Smouse and Sork (2004) outlined three main trends for this parameter: (1) wind pollinated species show higher $N_{\mathrm{ep}}$-values than animal pollinated species; (2) trees with a higher conspecific density have higher $N_{\text {ep }}$ (eg El-Kassaby and Jaquish, 1996); (3) The density of other species impedes pollen dispersal yielding higher $N_{\text {ep }}$ estimates in stands with more open canopies (eg Dyer and Sork, 2001).

Our overall estimate of $N_{\mathrm{ep}}=100$, is similar to estimates from other conifer species. In Pinus sylvestris, $N_{\text {ep }}>70$ (Robledo-Arnuncio et al, 2004), in Larix occidentalis, $N_{\text {ep }}$ ranges from 10 to 1000 (El-Kassaby and Jaquish, 1996) and in Thuja plicata, $N_{\mathrm{ep}}=40$ (O'Connell et al, 2001). In contrast, $N_{\text {ep }}$ between 1 and 2 was estimated from a paternity analysis in a seed orchard of white spruce (Schoen and Stewart, 1986; Smouse and Sork, 2004). In the seed orchard study, however, pollen from outside the orchard was not considered, even though it was only isolated by $1 \mathrm{~km}$ from natural white spruce stands. As the results of our study show, a considerable amount of pollen can travel over this distance in white spruce and the actual $N_{\mathrm{ep}}$ in the seed orchard study is probably much larger. Unlike conifers, wind-pollinated oaks and animal-pollinated species tend to show much lower estimates of $N_{\text {ep }}$ (Smouse and Sork, 2004). In general, $N_{\text {ep }} \leq 12$ has been reported for these nonconiferous species. One exception is Acacia melaxylon, where estimates of $N_{\text {ep }}$ range from 16 to 33 (Muona et al, 1991).

Although there was no significant difference in conspecific tree density among SSCs in our study, we found that $N_{\mathrm{ep}}$ was smaller $(<50 \%)$ in small stands, than in medium-sized and large stands. This result is consistent with pollen-limitation that we observed in these small stands (O'Connell et al, 2006). If a proportion of the seeds are sired by local trees, and there are a few dominant males in a stand, we would also expect some correlation of paternity, especially in small stands with only a few trees. In fact, we have found a slightly higher correlation of paternity, and thus a lower estimate of $N_{\mathrm{ep}}$ in small stands than in medium-sized and large stands. Nevertheless, correlation of paternity in small stands was still very low $\left(r_{\mathrm{p}}=1.6 \%\right)$ and $N_{\text {ep }}$ was high for all SSCs.

While previous studies suggest that a reduction in the surrounding canopy can increase pollen flow (Young and Merriam, 1994; Dyer and Sork, 2001) we did not find any evidence of this in our more fragmented (ie small) stands. All stands regardless of size were relatively open and probably experienced high levels of gene flow. The reduction in the total amount of pollen received in small stands could have increased the proportion of the pollen cloud made up by pollen contributed by local trees. However, we failed to detect any differentiation in the pollen pool among small stands.

Estimates of $N_{\mathrm{ep}}$ calculated from $\Phi_{\mathrm{FT}}$ did not correlate well with estimates of $N_{\text {ep }}$ calculated from $r_{\mathrm{p}}$. We found significant differentiation among pollen pools in trees from medium-sized stands, but no differentiation among pollen pools in trees from the small or large stands. Possible reasons for this discrepancy between the two estimates are: (1) the medium SSC showed the lowest outcrossing rate (Table 2), which could inflate the estimate of $\Phi_{\mathrm{FT}}$. However, the observed differences in outcrossing rates among the groups are probably not large enough to account for the pollen pool differentiation (Burczyk and Koralewski, 2005). (2) The data set we used for MLTR to estimate $r_{\mathrm{p}}$ also included megagametophyte genotype data for approximately $10 \%$ of the seeds, leading to a more accurate estimate of mating system parameters. Nevertheless, the overall estimate of $\Phi_{\mathrm{FT}}$ was negative, and like $r_{\mathrm{p}}$, suggests there was very little pollen pool structure in these fragmented white spruce stands.

\section{Genetic diversity of filial population}

The results of our study demonstrate that the SSC and fragmentation did not adversely affect the genetic diversity of the filial seed population in white spruce. There was remarkably little difference in filial genetic diversity among SSCs, considering the more than 100fold difference in the number of trees per stand. This lack of differentiation is especially marked between the medium-sized and large stands where equal sample sizes make it possible to directly compare the levels of genetic diversity among filial populations. Although 
primary selfing rates were lower in large stands, genetic diversity of the resultant seed did not differ significantly from seeds from medium-sized stands. Trees in the medium-sized stands showed the highest levels of primary selfing, yet also had the filial populations with the highest levels of genetic diversity. As the primary selfing rate is partially estimated from the empty seed data (inbred embryos that have been aborted), the viable, and thus assayed seeds will represent the more heterozygous individuals. The elimination of inbred and less genetically heterozygous embryos is therefore one of the primary mechanisms that maintains genetic diversity in conifers.

Genotypic diversity measures $\left[\left(G_{\mathrm{A}}(O)\right.\right.$ and $\left.\left.G_{\mathrm{A}}(E)\right)\right]$ and $L G P$ did not differ significantly between the mediumsized and large stands. However, these measures were all lower in the small SSC. This was mainly due to smaller number of maternal genotypes in these stands. As all families were sampled in these small stands, these are accurate measures of the genotypic diversity of these stands that show the limited number of genotypes possible in small stands. Limited seed dispersal may lower genotypic diversity in isolated stands in the short term. Nevertheless, because of the high gene flow, as suggested by the outcross pollen pool allele frequencies, the loss of genotypes in these small stands may potentially be recovered in subsequent generations.

The lack of differentiation in genetic diversity among filial populations can be directly attributed to the genetic diversity of the pollen pool that arises from panmixia. Measures of genetic diversity of the pollen pool were similar in all SSCs. The low number of alleles detected in the filial population and outcross pollen pool of small stands is probably due to a smaller sample size in this SSC. Gene diversity and allelic richness were both corrected for differences in sample size and did not differ among SSCs (Tables 4 and 5).

\section{Conclusions}

In this study, we detected a low impact of fragmentation on the mating system of the parental population and the genetic diversity of the filial population of white spruce. We found a reduction in the number of effective pollen parents $\left(N_{\mathrm{ep}}\right)$ in small stands, but the resultant seed maintained high levels of diversity. Genetic data from seed populations alone may overstate outcrossing rates if inbreeding depression has lethal effects that occur very early in the development of seeds. Inbreeding depression could, therefore, mask the negative genetic effects of fragmentation in seed populations. Molecular markers also do not detect other impacts of habitat disturbance on reproductive fitness of natural populations. We have previously found that small and isolated stands are likely to be pollen-limited, and have a significantly lower overall fecundity (ie number of viable seeds per cone) than larger stands and contiguous forests ( $\mathrm{O}^{\prime}$ Connell et al, 2006).

Nevertheless, the resultant seeds in fragmented and geographically isolated stands maintain high levels of heterozygosity and allelic richness. These results are significant for conifers, and trees in general, that are well-known for their high genetic diversity (Hamrick and Godt, 1996). The selection against inbred seeds and seedlings, may partly explain how trees maintain such a high heterozygosity. Our results also show that high gene flow between stands also contributes to the high genetic diversity of seeds produced in small, geographically isolated stands. In this study, we provide strong empirical evidence of extensive gene flow over a landscape capable of maintaining high genetic diversity and connectivity between populations of a common temperate conifer. White spruce is representative of most temperate conifers, which usually show high outcrossing rates and high genetic diversity. The source of pollen and the quantification of pollen-mediated gene flow into these small isolated stands of white spruce are addressed in another manuscript ( $\mathrm{O}^{\prime}$ Connell, Mosseler and Rajora, unpublished).

\section{Acknowledgements}

We thank B Arsenault and L DeVerno for assistance with isozyme electrophoresis, L Dobrich for locating stands and collecting seeds, J Lavereau for the cone and seed processing and YS Park, J Major and V Sork for comments on an earlier version of the manuscript. LM O'Connell was supported by a Natural Sciences and Engineering Research Council of Canada (NSERC) Postdoctoral Visiting Fellowship funded by the Canadian Forest Service (CFS) and an NSERC Postdoctoral Fellowship at UNB. OP Rajora held the Stora Enso Senior Chair in Forest Genetics and Biotechnology at Dalhousie University, which was supported by Stora Enso Port Hawkesbury Ltd, and holds the Senior Canada Research Chair in Forest and Conservation Genomics and Biotechnology at UNB, which is supported by Canada Research Chair Program. The research was funded by an NSERC Discovery Grant to OP Rajora and CFS operating funds to A Mosseler.

\section{References}

Aldrich PR, Hamrick JL (1998). Reproductive dominance of pasture trees in a fragmented tropical forest mosaic. Science 281: 103-105.

Austerlitz F, Smouse PE (2001). Two-generation analysis of pollen flow across a landscape. II. Relation between $\Phi_{\mathrm{FT}}$, pollen dispersal, and inter-female distance. Genetics 157: 851-857.

Bacles CFE, Lowe AJ, Ennos RA (2004). Genetic effects of chronic habitat fragmentation on tree species: the case of Sorbus aucuparia in a deforested Scottish landscape. Mol Ecol 13: 573-584.

Bergmann F, Gregorius H-R, Larsen JB (1990). Levels of genetic variation in European silver fir (Abies alba): are they related to species decline? Genetica 82: 1-10.

Burczyk J, Koralewski TE (2005). Parentage versus twogeneration analyses for estimating pollen-mediated gene flow in plant populations. Mol Ecol 14: 2525-2537.

Cascante A, Quesada M, Lobo JJ, Fuchs EA (2002). Effects of dry tropical forest fragmentation on the reproductive success and genetic structure of the tree Samanea saman. Cons Biol 16: 137-147.

Casgrain P, Legendre P (2001). The R Package for multivariate and spatial analysis, version 4.0- User's Manual URL: 〈http:// www.fas.umontral.ca/BIOL/legendre/ $\rangle$. Département de Sciences Biologiques, Université de Montréal, Montréal, Québec.

Cheliak WM, Pitel JA (1984). Techniques for starch gel electrophoresis of enzymes from forest tree species. Petawawa National 
Forestry Institute, Agriculture Canada, Canadian Forestry Service.

Cheliak WM, Pitel JA, Murray G (1985). Population structure and the mating system of white spruce. Can J For Res 15: 301-308.

Collevatti RG, Grattapaglia D, Hay JD (2001). Population genetic structure of the endangered tropical tree species Caryocar brasiliense, based on variability at microsatellite loci. Mol Ecol 10: 349-356.

Denti D, Schoen DJ (1988). Self-fertilization rates in white spruce: effect of pollen and seed production. J Hered 79 284-288.

Dyer R, Sork V (2001). Pollen pool heterogeneity in shortleaf pine, Pinus echinata Mill. Mol Ecol 10: 859-866.

El-Kassaby YA, Jaquish B (1996). Population density and mating patterns in western larch. J Hered 87: 438-443.

Farris MA, Mitton JB (1984). Population density, outcrossing rate, and heterozygote superiority in ponderosa pine. Evolution 38: 1151-1154.

Fowler DP, Park YS (1983). Population studies of white spruce. I Effects of self-pollination. Can J Forest Res 13: 1133-1138.

Furnier GR, Stine M, Mohn CA, Clyde MA (1991). Geographic patterns of variation in allozymes and height growth in white spruce. Can J Forest Res 21: 707-712.

Fuchs EJ, Lobo JA, Quesada M (2003). Effects of forest fragmentation and flowering phenology on the reproductive success and mating patterns of the tropical dry forest tree Pachira quinata. Cons Biol 17: 149-157.

Goudet J (2001). FSTAT, a program to estimate and test gene diversities and fixation indices. Available from http:// www.unil.ch/izea/softwares/fstat.html.

Hall P, Walker S, Bawa K (1996). Effect of forest fragmentation on genetic diversity and mating system in a tropical tree, Pithecellobium elegans. Cons Biol 10: 757-768.

Hamrick JL, Godt MJW (1996). Effects of life history traits on genetic diversity in plant species. Phil Trans Roy Soc Lond B 351: 1291-1298.

Hebert PDN, Beaton MJ (1989). Methodologies for allozyme analysis using cellulose acetate electrophoresis Available from $\langle$ http://www.cladocera.uoguelph.ca/tools $\rangle$.

Innes DJ, Ringius GG (1990). Mating system and genetic structure of two populations of white spruce (Picea glauca) in eastern Newfoundland. Can J Bot 68: 1661-1666.

Mantel NA (1967). The detection of disease clustering and a generalized regression approach. Cancer Res 27: 209-220.

Mitton JB (1992). The dynamic mating systems of conifers. New For 6: 197-216.

Muona O, Moran GF, Bell JC (1991). Hierarchical patterns of correlated mating in Acacia melanoxylon. Genetics 127: 619626.

Nason JD, Hamrick JL (1997). Reproductive and genetic consequences of forest fragmentation: two case studies of Neotropical canopy trees. J Hered 88: 264-276.

Nienstaedt H, Zasada JC (1990). Picea glauca (Moench) Voss white spruce. In: Burns RM, Honkala BH (eds) Silvics of North America. Volume 1. Conifers. Agricultural Handbook 654. Department of Agriculture, Forest Service: Washington DC. pp 204-226.

O'Connell LM, Viard F, Russell J, Ritland K (2001). The mating system in natural populations of western redcedar (Thuja plicata). Can J Bot 79: 753-756.

O'Connell LM, Russell J, Ritland K (2004). Fine-scale estimation of outcrossing in western redcedar with microsatellite assay of bulked DNA. Heredity 93: 443-449.
O'Connell LM, Mosseler A, Rajora OP (2006). Impacts of forest fragmentation on the reproductive success in white spruce (Picea glauca). Can J Bot 84: 956-965.

Owens JN, Molder M (1979). Sexual reproduction of white spruce (Picea glauca). Can J Bot 57: 152-169.

Rajora OP (1999). Genetic biodiversity impacts of silvicultural practices and phenotypic selection in white spruce. Theor Appl Genet 99: 954-961.

Rajora OP, Dancik BP (2000). Population genetic structure, variation and evolution of Engelmann spruce, white spruce and their putative natural hybrid complex in Alberta. Can J Bot 78: 768-780.

Rajora OP, Mosseler A, Major JE (2000a). Indicators of population viability in red spruce, Picea rubens. II. Genetic diversity, population structure, and mating behaviour. Can J Bot 78: 941-956.

Rajora OP, Rahman MH, Buchert GP, Dancik BP (2000b). Microsatellite DNA analysis of genetic effects of harvesting in old-growth eastern white pine (Pinus strobus) in Ontario. Mol Ecol 9: 339-348.

Rajora OP, Mosseler A, Major JE (2002). Mating system and reproductive fitness traits of eastern white pine (Pinus strobus) in large, central versus small, isolated, marginal populations. Can J Bot 80: 1173-1184.

Raymond M, Rousset F (1995). GENEPOP version 1.2: population genetics software for the exact tests and ecumenism. J Hered 86: 248-249.

Reed DH (2005). Relationship between population size and fitness. Cons Biol 19: 563-568.

Ritland K (1989). Correlated matings in the partial selfer, Mimulus guttatus. Evolution 43: 848-859.

Ritland K (2002). Extensions of models for the estimation of mating systems using $n$ independant loci. Heredity 88: 221-228.

Robledo-Arnuncio JJ, Smouse PE, Gil L, Alia R (2004). Pollen movement under alternative silvicultural practices in native populations of Scots Pine (Pinus sylvestris L) in central Spain. For Ecol Manag 197: 245-255.

SAS Institute (1997). JMP User's Guide. SAS Institute Inc: Cary, NC.

Schoen DJ, Stewart SC (1986). Variation in male reproductive investment and male reproductive success in white spruce. Evolution 40: 1109-1121.

Smouse PE, Dyer RJ, Westfall RD, Sork VL (2001). Twogeneration analysis of pollen flow across a landscape. I. Male gamete heterogeneity among females. Evolution 55: 260-271.

Smouse PE, Sork VL (2004). Measuring pollen flow in forest trees: A comparison of alternative approaches. For Ecol Manag 197: 21-38.

Stebbins GL, Hartl DL (1988). Comparative evolution: Latent potentials for anagenetic advance. Proc Natl Acad Sci (USA) 85: 5141-5145.

Vergeer P, Rengelink P, Copal A, Ouborg NJ (2003). The interacting effects of genetic variation, habitat quality and population size on performance of Succisa pratensis. J Ecol 91: $18-26$.

Weir BS, Cockerham CC (1984). Estimating F-statistics for the analysis of population structure. Evolution 38: 1358-1370.

Young A, Boyle T, Brown T (1996). The population genetic consequences of habitat fragmentation for plants. Trends Ecol Evol 11: 413-418.

Young AG, Merriam HG (1994). Effects of forest fragmentation on the spatial genetic structure of Acer saccharum Marsh. (sugar maple) populations. Heredity 72: 201-208. 